Bull. Mater. Sci., Vol. 36, No. 3, June 2013, pp. 403-409. (c) Indian Academy of Sciences.

\title{
Effect of power variation on wettability and optical properties of co-sputtered titanium and zirconium oxynitride films
}

\author{
SUSHANT K RAWAL ${ }^{\mathrm{a}, \mathrm{b}, \mathrm{e}}$, AMIT KUMAR CHAWLA ${ }^{\mathrm{c}}$, R JAYAGANTHAN ${ }^{\mathrm{a}, \mathrm{d}}$ \\ and RAMESH CHANDRA ${ }^{\mathrm{b}, *}$ \\ ${ }^{\mathrm{a} C e n t r e}$ of Nanotechnology, ${ }^{\mathrm{b}}$ Nano Science Laboratory, Institute Instrumentation Centre, Indian Institute of Technology \\ Roorkee, Roorkee 247 667, India \\ ${ }^{\mathrm{c}}$ Department of Physics, University of Petroleum and Energy Studies, Dehradun 248 007, India \\ ${ }^{\mathrm{d}}$ Department of Metallurgical and Materials Engineering, Indian Institute of Technology Roorkee, Roorkee 247 667, India \\ ${ }^{\mathrm{e}}$ CHAMOS Matrusanstha Department of Mechanical Engineering, Charotar University of Science and Technology, \\ Changa 388 421, India
}

MS received 4 August 2011; revised 4 February 2013

\begin{abstract}
The present paper deals with deposition of titanium and zirconium oxynitride films prepared from cosputtering titanium and zirconium targets by reactive RF magnetron sputtering. The effect of power variation on various properties of the deposited films is analysed. The film gets transformed from amorphous to well crystalline oxynitride films with gradual increase of target powers as observed from XRD graphs. The films exhibit hydrophilic and hydrophobic behaviours depending upon the presence of various phases. Surface energy decreases as the film properties change from hydrophilic to hydrophobic due to greater contact angle values. The optical properties were measured by UV-Vis-NIR spectrophotometer, transmission spectra and bandgap values show variation with respect to change in elemental composition as determined from EDS analysis.
\end{abstract}

Keywords. Titanium oxynitride; zirconium oxynitride; co-sputtering; contact angle; surface energy; optical properties.

\section{Introduction}

Metal oxynitrides, $\mathrm{MeO}_{x} \mathrm{~N}_{y}(\mathrm{Me}=$ transition metal), belong to a new class of materials that is gaining importance because of their high potential as decorative applications in high quality consumer products (Moura et al 2006). Metal oxynitrides films are formed by adding nitrogen in transition metal oxides or oxygen in transition metal nitrides. Such a substitution holds the promise to change in structural and optical properties since metal-nitrogen bonds tend to be less polar than the corresponding metal-oxygen bonds. Even though the replacement of oxygen ions by nitrogen ions appears potentially attractive, only few research groups have tried to exploit the potential of these materials (Ohring 1991; Venkataraj et al 2002).

In particular, titanium oxynitride and zirconium oxynitride films have gained scientific interest because they benefit from the properties of both metallic oxides (colours, optical properties, chemical stability) and metallic nitrides (hardness, wear resistance) (Chappe et al 2006; Rizzo et al 2009). Titanium oxynitride films are subjected to numerous applications due to their physicochemical properties which are dependent

\footnotetext{
*Author for correspondence (ramesfic@gmail.com)
}

on $\mathrm{N} / \mathrm{O}$ ratio. Therefore, oxygen-rich titanium oxynitride films are widely employed as insulating layers in metalinsulator-metal (MIM) capacitive structures, while nitrogenrich titanium oxynitride films have been successfully used as diffusion barriers (Kazemeini et al 2000; Scopel et al 2002; Braic et al 2007; Trapalis et al 2007). They exhibit interesting properties for applications in the fields ranging from protective decorative coatings to solar panels (Alves et al 2004).

Zirconium oxynitride system is stimulating curiosity in renewable energy research field to produce hydrogen by direct water splitting on a specific photocatalyst using solar energy (Bard and Fox 1995). In fact, zirconium oxynitride has been indicated as a suitable photocatalytic material active under visible-light irradiation and this is an attractive option due to the limited number of photocatalytic materials for this purpose (Maeda et al 2006; Signore et al 2010). These have potential applications such as decorative coatings (Carvalho et al 2005; Mohamed et al 2007), anti-corrosion coatings (Ariza et al 2004), dielectrics (Nieh et al 2003) and sensors (Brandt et al 1999).

Methods of oxynitrides preparation include chemical vapour deposition (CVD), reactive cathodic arc evaporation (Laurikaitis et al 2008), physical vapour deposition (PVD) (Venkataraj et al 2002; Vaz et al 2004), etc. Out of all these methods the sputtering technique is one of the PVD methods 
most commonly used for thin films deposition. Its popularity is due to the simplicity of involved physical processes, to the versatility of this technique and to the possibilities to control several parameters during the deposition procedure (Pacheco et al 2009). The main advantage of using reactive magnetron sputtering for preparing metal oxynitride coatings is that we can carefully monitor the percentage of $\mathrm{N}$ and $\mathrm{O}$ in the sample by changing the flow rates of reactive gases like oxygen and nitrogen.

In this study, we have tried to deposit titanium and zirconium oxynitride films by co-sputtering from titanium and zirconium targets. The flow rate of reactive gases (oxygen and nitrogen) was kept constant and helium was used as an inert gas during sputtering. The systematic variation of power of the two targets on structural, optical and hydrophilic/ hydrophobic properties are investigated.

\section{Experimental}

Two metallic targets of titanium and zirconium (99.99\% pure, 2 in. diameter and $5 \mathrm{~mm}$ thick) were used by RF magnetron sputtering to deposit oxynitride coatings on corning 1737 glass substrates. The targets were arranged confocally for co-sputtering and the substrate to target distance was kept constant at $50 \mathrm{~mm}$ during deposition. The substrates were cleaned by rinsing in ultrasonic baths of acetone and methanol. The base pressure was better than $5 \times 10^{-4} \mathrm{~Pa}$ and the sputtering was carried out in helium atmosphere along with oxygen and nitrogen as reactive gases. The deposition time, temperature and gas pressure were kept constant at $60 \mathrm{~min}, 500{ }^{\circ} \mathrm{C}$ and $2 \mathrm{~Pa}$, respectively for all depositions. Before starting the actual experiment, targets were presputtered for 15 min with a shutter located in between the target and the substrate. This shutter is also used to control the deposition time. First the power of zirconium target was kept constant at $30 \mathrm{~W}$ and the power of titanium target was varied as 60,90 and $120 \mathrm{~W}$, respectively represented by samples TZ-1, TZ-2 and TZ-3. Sample TZ was deposited by keeping the power of both targets at $75 \mathrm{~W}$. Finally the power of titanium target was kept fixed at $30 \mathrm{~W}$ and power of zirconium target was varied as 60,90 and $120 \mathrm{~W}$ which are represented by samples ZT-1, ZT-2 and ZT-3.

Structural characterization of the deposited samples was done by X-ray diffractometer (XRD) using Bruker D8 Advance diffractometer with $\mathrm{Cu} \mathrm{K} \alpha$ radiation of wavelength $1.54 \AA$. The surface morphology of films was characterized using atomic force microscope (NT-MDT Ntegra). The elemental analysis of these films was carried out using an energy dispersive X-ray analysis (FEI, Quanta 200F). The wettability studies of films were done by contact angle measurement system (Kruss DSA 100 Easy Drop) to find the contact angle of water with films. The thickness of samples was determined by Surface Profilometer (Ambios Technology XP200). Optical transmission and absorption of the films were measured by UV-Vis-NIR spectrophotometer (Varian Cary 5000)

\section{Results and discussions}

Structural variations of the deposited films at different power combinations of both targets were observed by X-ray diffraction technique. Figure 1 shows XRD graphs of deposited titanium oxynitride and zirconium oxynitride films. Sample TZ-1 which is deposited at $60 \mathrm{~W}$ of Ti target and $30 \mathrm{~W}$ of $\mathrm{Zr}$ target power is amorphous as observed from XRD graphs. The $\left(\begin{array}{lll}1 & 0 & 1\end{array}\right)$ oriented peak of anatase $\mathrm{TiO}_{2}$ phase is observed for sample TZ-2 when the power of Ti target is $90 \mathrm{~W}$. Further increase of Ti power to $120 \mathrm{~W}$ for sample TZ-3 shows (2 00 ) oriented anatase $\mathrm{TiO}_{2}$ phase along with $\left(\begin{array}{lll}1 & 0 & 1\end{array}\right)$ oriented peak of anatase $\mathrm{TiO}_{2}$. A weak crystalline ( 002 2) peak of TiN phase is also observed for the same condition. During all the three depositions, power of $\mathrm{Zr}$ target was kept constant at $30 \mathrm{~W}$.

When the power of Ti target is fixed at $30 \mathrm{~W}$ and the power of $\mathrm{Zr}$ target is kept at $60 \mathrm{~W}$ for sample ZT-1, the deposited film is amorphous by nature. The films show a mixed structure of $m-\mathrm{ZrO}_{2}$ phase with (1 111 ) orientation along with (2 2 2 ) and (4 40 ) textured $\gamma-\mathrm{Zr}_{2} \mathrm{ON}_{2}$ phase at $90 \mathrm{~W}$ power of $\mathrm{Zr}$ target for sample ZT-2. Further increase of $\mathrm{Zr}$ target power to $120 \mathrm{~W}$ shows the formation of $\left(\begin{array}{lll}4 & 0 & 0\end{array}\right)$ and $\left(\begin{array}{lll}3 & 1 & 1\end{array}\right)$ ori-

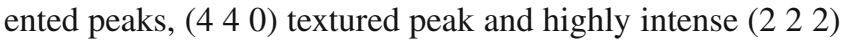
$\gamma-\mathrm{Zr}_{2} \mathrm{ON}_{2}$ phase for sample ZT-3 which was also observed by Carvalho et al (2008). When the powers of both targets were kept at $75 \mathrm{~W}$ for sample $\mathrm{TZ}$, it shows the formation of (1 111 ) oriented $m-\mathrm{ZrO}_{2}$ phase with no trace of titanium oxide or nitride phase. The average crystallite size was calculated from Scherrer formula (Cullity 1978) which is almost constant for all the samples under study. The average crystallite

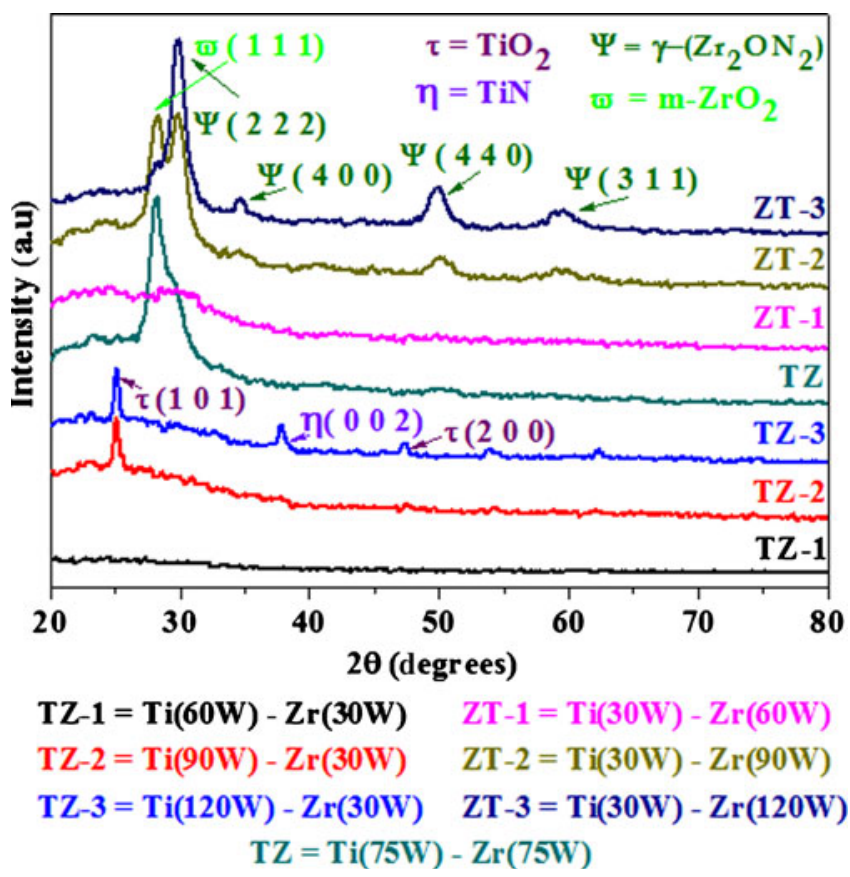

Figure 1. XRD micrographs of titanium and zirconium oxynitride films at varying powers of $\mathrm{Ti}$ and $\mathrm{Zr}$ targets. 
Table 1. Calculated parameters of titanium and zirconium oxynitride thin films.

\begin{tabular}{|c|c|c|c|c|c|c|c|c|}
\hline Samples & Sputtering power of targets & $\begin{array}{c}\mathrm{Ti} \\
\text { (at \%) }\end{array}$ & $\begin{array}{c}\mathrm{Zr} \\
\text { (at \%) }\end{array}$ & $\begin{array}{c}\mathrm{O} \\
(\text { at } \%)\end{array}$ & $\begin{array}{c}\mathrm{N} \\
\text { (at \%) }\end{array}$ & $\begin{array}{c}\text { Avg. } \\
d_{(\mathrm{XRD})}(\mathrm{nm})\end{array}$ & $\begin{array}{c}\text { Bandgap } \\
(\mathrm{eV})\end{array}$ & $\begin{array}{l}\text { Thickness }(\mathrm{nm}) \\
\text { by profilometer }\end{array}$ \\
\hline TZ-1 & $\mathrm{Ti}(60 \mathrm{~W})-\mathrm{Zr}(30 \mathrm{~W})$ & 16 & 13 & 71 & 00 & - & $2 \cdot 05$ & 121 \\
\hline $\mathrm{TZ}-2$ & Ti $(90 \mathrm{~W})-\mathrm{Zr}(30 \mathrm{~W})$ & 31 & 05 & 64 & 00 & 49 & $2 \cdot 26$ & 288 \\
\hline $\mathrm{TZ}-3$ & Ti $(120 \mathrm{~W})-\mathrm{Zr}(30 \mathrm{~W})$ & 35 & 02 & 60 & 03 & 48 & $2 \cdot 45$ & 354 \\
\hline $\mathrm{TZ}$ & Ti $(75 \mathrm{~W})-\mathrm{Zr}(75 \mathrm{~W})$ & 19 & 26 & 55 & 00 & 7 & $2 \cdot 64$ & 161 \\
\hline ZT-1 & $\mathrm{Ti}(30 \mathrm{~W})-\mathrm{Zr}(60 \mathrm{~W})$ & 10 & 21 & 69 & 00 & - & $2 \cdot 55$ & 223 \\
\hline ZT-2 & $\mathrm{Ti}(30 \mathrm{~W})-\mathrm{Zr}(90 \mathrm{~W})$ & 04 & 39 & 52 & 05 & 10 & $3 \cdot 15$ & 319 \\
\hline ZT-3 & $\mathrm{Ti}(30 \mathrm{~W})-\mathrm{Zr}(120 \mathrm{~W})$ & 02 & 47 & 43 & 08 & 9 & $3 \cdot 25$ & 348 \\
\hline
\end{tabular}
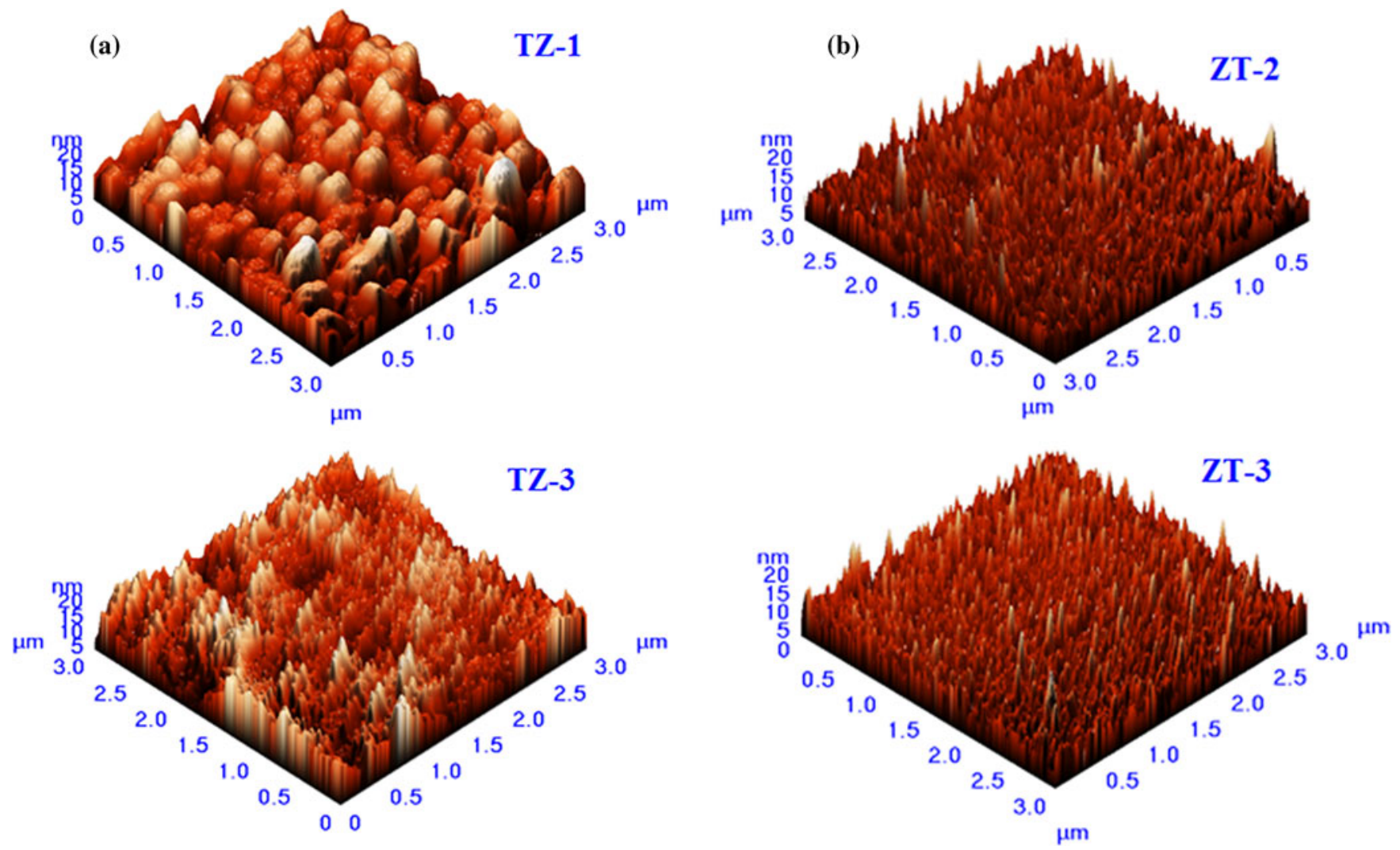

Figure 2. AFM micrographs of (a) titanium oxynitride films at varying powers of Ti target and (b) zirconium oxynitride films at varying powers of $\mathrm{Zr}$ target.

size is given in table 1 which is around $49 \mathrm{~nm}$ for titanium oxynitride films and $10 \mathrm{~nm}$ for zirconium oxynitride films.

The possible reason for the amorphous nature of the deposited films for samples TZ-1 [Ti $(60 \mathrm{~W})-\mathrm{Zr}(30 \mathrm{~W})]$ and ZT-1 [Ti $(30 \mathrm{~W})-\mathrm{Zr}(60 \mathrm{~W})]$ may be due to low values of target powers. Due to the low power of both the targets, proportion of the metal atoms reaching the substrate is less as evident from EDS data. So they might not have sufficient energy to arrange themselves in crystalline form leading to very low deposition rate of deposited films. Moreover, the observed phases at high values of target powers viz. $\mathrm{TiO}_{2}$ and TiN for sample TZ-3 whereas $m-\mathrm{ZrO}_{2}$ and $\gamma-\mathrm{Zr}_{2} \mathrm{ON}_{2}$ for samples ZT-2 and ZT-3 are all having different structures. So metal atoms ( $\mathrm{Ti}$ and $\mathrm{Zr}$ ) will try to form the particular phases but initially due to low values of targets power the relative energy of metal atoms required to form the respective phases are inadequate leading to deposition of amorphous films. When the power of both targets are kept equal only $m-\mathrm{ZrO}_{2}$ phase is observed in XRD graphs for sample $\mathrm{TZ}$. The possible reason for this may be due to the difference in Gibbs free energy for the formation of metal oxides and nitrides. Gibbs free energy is minimum for the formation of metal oxides as compared to metal nitrides. Further Gibbs energy value for zirconium dioxide formation is less as compared to titanium dioxide (Liang and Schuster 1982; Kostov and Friedrich 2005). So at the same power values of both the targets $\mathrm{Zr}$ atoms proportion is higher compared to $\mathrm{Ti}$ atoms as per EDS data given in table 1 and due to lower Gibbs energy 
values of zirconium dioxide it favourably leads to the formation of $m-\mathrm{ZrO}_{2}$ phase. This may also be the possible reason that first the metal oxides are formed preferably due to their low Gibbs energy and then only the nitrides i.e. TiN and $\gamma$ $\mathrm{Zr}_{2} \mathrm{ON}_{2}$ phases are observed at high powers of targets when adequate metal atoms with sufficient energies are available to form nitride and oxynitride phases.

AFM micrographs of samples TZ-1 and TZ-3 for titanium oxynitride films and samples ZT-2 and ZT-3 for zirconium oxynitride films are shown in figures 2a,b), respectively. Average crystallite size is almost constant for both the cases. Less surface roughness is observed at lower values of target powers for both the cases. As reported in literature, higher surface roughness is observed with increase in films thickness (Hsu et al 2006). Also amorphous films show lower surface roughness values as compared to well crystalline films (Hones et al 1999). As reported in literature, the increase of power of sputtered target increases the number of ionized gas ions that results in increase of sputtered atoms off the target, therefore, leading to a higher growth rate (Kuo and Chien
2003). Hence with the gradual increase of power of both targets the deposition rate increases which results in the formation of various phases. Thickness of the deposited films measured by surface profilometer is summarized in table 1 . The thickness of titanium oxynitride and zirconium oxynitride films which increases with the power of respective targets, along with the formation of well crystalline films which increases the surface roughness values.

Surface roughness is related to contact angle by Wenzel equation discussed in detail elsewhere (Wu et al 2006). Sessile drop technique was used for determining the contact angle, ten observations were taken and the average value is shown in figure 3 . The surface energy of solid is explained by Young's equation (Young 1805; Chen et al 2001), but further relation is derived by Owens and Wendl (1969) geometric mean approach and Wu-harmonic mean approach (Chiu et al 2006). Surface energy has two main components, polar and dispersive and to determine them two liquids viz. water and diiodomethane the latter having zero polar component value, are used and the results are summarized in table 2.

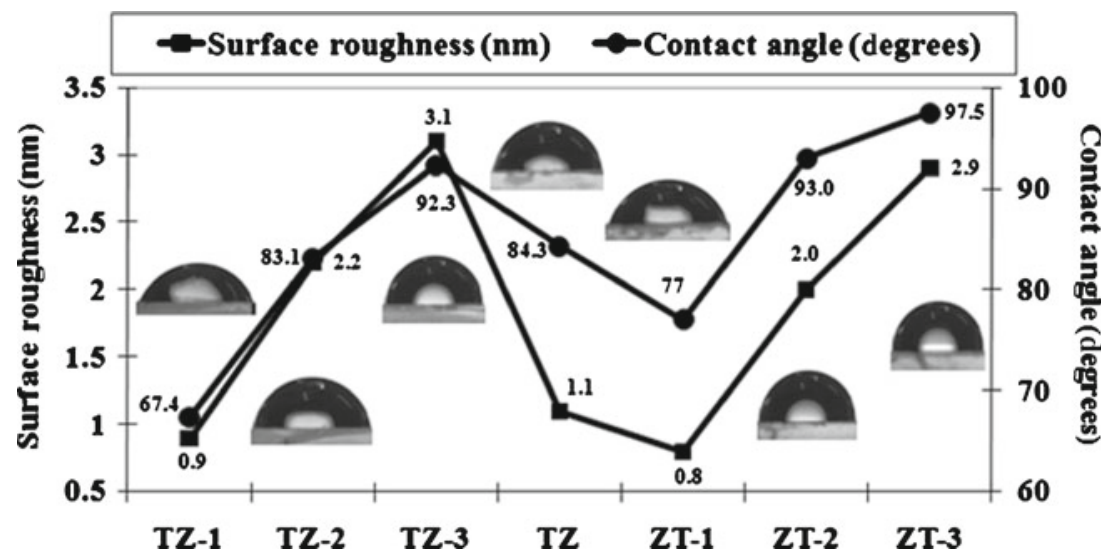

Figure 3. Variation of contact angle with surface roughness for titanium and zirconium oxynitride films at varying powers of $\mathrm{Ti}$ and $\mathrm{Zr}$ targets.

Table 2. Calculation results of dispersion component, polar component and surface energy of deposited titanium and zirconium oxynitride films.

\begin{tabular}{|c|c|c|c|c|c|c|}
\hline \multicolumn{7}{|c|}{ Parameters of liquids used in evaluating surface energy } \\
\hline \multicolumn{3}{|r|}{$\gamma_{\mathrm{L}}(\mathrm{mN} / \mathrm{m})$} & $\left(\gamma_{\mathrm{L}}^{d}\right)(\mathrm{mN} / \mathrm{m})$ & $\left(\gamma_{\mathrm{L}}^{\mathrm{P}}\right)$ & & \\
\hline \multirow{2}{*}{\multicolumn{2}{|c|}{$\begin{array}{l}\text { Water }\left(\mathrm{H}_{2} \mathrm{O}\right) \\
\text { Diiodomethane }\left(\mathrm{CH}_{2} \mathrm{I}_{2}\right)\end{array}$}} & $72 \cdot 8$ & $21 \cdot 8$ & 51 & & \\
\hline & & $50 \cdot 8$ & $50 \cdot 8$ & 0 & & \\
\hline \multirow[b]{2}{*}{ Sample name } & \multicolumn{3}{|c|}{ Owens-Wendt Method } & \multicolumn{3}{|c|}{ Wu method } \\
\hline & $\gamma_{\mathrm{S}}(\mathrm{mN} / \mathrm{m})$ & $\left(\gamma_{\mathrm{S}}^{\mathrm{d}}\right)(\mathrm{mN} / \mathrm{m})$ & $\left(\gamma_{\mathrm{S}}^{\mathrm{p}}\right)(\mathrm{mN} / \mathrm{m})$ & $\overline{\gamma_{\mathrm{S}}(\mathrm{mN} / \mathrm{m})}$ & $\left(\gamma_{\mathrm{S}}^{\mathrm{d}}\right)(\mathrm{mN} / \mathrm{m})$ & $\left(\gamma_{\mathrm{S}}^{\mathrm{p}}\right)(\mathrm{mN} / \mathrm{m})$ \\
\hline $\mathrm{TZ}-1$ & $38 \cdot 70$ & $24 \cdot 15$ & $14 \cdot 56$ & $44 \cdot 34$ & $26 \cdot 73$ & $17 \cdot 61$ \\
\hline $\mathrm{TZ}-2$ & $25 \cdot 54$ & $15 \cdot 94$ & $9 \cdot 61$ & $32 \cdot 23$ & $19 \cdot 76$ & $12 \cdot 47$ \\
\hline $\mathrm{TZ}-3$ & $18 \cdot 63$ & $11 \cdot 62$ & $7 \cdot 01$ & $25 \cdot 73$ & $15 \cdot 97$ & $9 \cdot 76$ \\
\hline $\mathrm{TZ}$ & $24 \cdot 36$ & $15 \cdot 20$ & $9 \cdot 16$ & $31 \cdot 13$ & $19 \cdot 12$ & $12 \cdot 01$ \\
\hline ZT-1 & $30 \cdot 57$ & $19 \cdot 07$ & $11 \cdot 50$ & $36 \cdot 86$ & 22.44 & 14.43 \\
\hline ZT-2 & $18 \cdot 29$ & 11.41 & $6 \cdot 88$ & $25 \cdot 40$ & $15 \cdot 78$ & 9.63 \\
\hline ZT-3 & $15 \cdot 27$ & $9 \cdot 53$ & 5.74 & 22.46 & $14 \cdot 04$ & 8.42 \\
\hline
\end{tabular}


The surface is termed hydrophilic if the contact angle is $<90^{\circ}$ and hydrophobic if the contact angle is $\geq 90^{\circ}$. For sample TZ-1, the deposited film shows low contact angle around $67.4^{\circ}$ and surface roughness of $0.9 \mathrm{~nm}$. For sample TZ-2, the contact angle and surface roughness values of $83.1^{\circ}$ and $2 \cdot 2 \mathrm{~nm}$ are measured, respectively thus depicting hydrophilic nature for the deposited films. Sample TZ-3 has greater contact angle of $92.3^{\circ}$ and surface roughness value of $3.1 \mathrm{~nm}$. Sample TZ has slightly lesser contact angle and surface roughness values as compared to sample TZ-3. Lower contact angle and surface roughness values are also observed for sample ZT-1 similar to sample TZ-1. Samples ZT-2 and ZT-3 are hydrophobic showing superior contact angle and higher surface roughness values as compared to ZT-1.

The surface morphology and surface chemical composition are two critical parameters that determine the surface energy of films (Chiu et al 2006). Moreover, contact angle shares direct relation with surface roughness and inverse relation to surface energy (Khudhayer et al 2009). The deposited films are amorphous at low target powers (samples TZ-1 and ZT-1) thus giving lower contact angle and higher surface energy values. From XRD graphs, the evolution of various phases for deposited titanium oxynitride films (samples TZ-2 and TZ-3) is observed at Ti target power $\geq 90 \mathrm{~W}$ and zirconium oxynitride films at $\mathrm{Zr}$ target power of $\geq 75 \mathrm{~W}$, respectively. For sample TZ-3, the anatase $\mathrm{TiO}_{2}$ phase with various textures along with TiN phase is observed. So the change from amorphous to well-structured morphology may be the reason for hydrophobicity of it imparting lower surface energy and greater contact angle values. In sample TZ, only $m-\mathrm{ZrO}_{2}$ phase is present whereas sample ZT-2 shows additional presence of $\gamma-\mathrm{Zr}_{2} \mathrm{ON}_{2}$ phase with different orientations. Further increase of power shows the presence of only $\gamma-\mathrm{Zr}_{2} \mathrm{ON}_{2}$ phase with various textures while $m-\mathrm{ZrO}_{2}$ phase is absent. EDS data reveals that the incorporation of nitrogen is observed only for samples TZ-3, ZT-2 and ZT-3. So this may lead to the formation of metal-nitrogen bond besides metaloxygen bond in the deposited films. It may be feasible only when the power of respective targets is high enough to generate metal atoms with sufficient energy to react with nitrogen and form metal-nitrogen bonding as the reactivity of oxygen (Martin et al 2001; Rizzo et al 2009) is higher compared to nitrogen thus favouring first the formation of oxide phases. So the change in surface morphology and chemical composition may be the possible reason for lower surface energy of these three samples thus imparting them hydrophobicity with contact angle values above $90^{\circ}$.

UV-Vis-NIR spectrophotometer is used for recording the transmittance and absorbance spectra for all samples and transmission spectra are shown in figure 4. The transmission of titanium oxynitride films is comparatively less than zirconium oxynitride films. Manifacier et al (1976) had proposed a model to calculate the refractive index of deposited films from the transmission spectra which is discussed in detail elsewhere (Chawla et al 2008). The film packing density can be determined using the expression of Bragg and Pippard model (Harris et al 1979; Xiao et al 2009). The variation

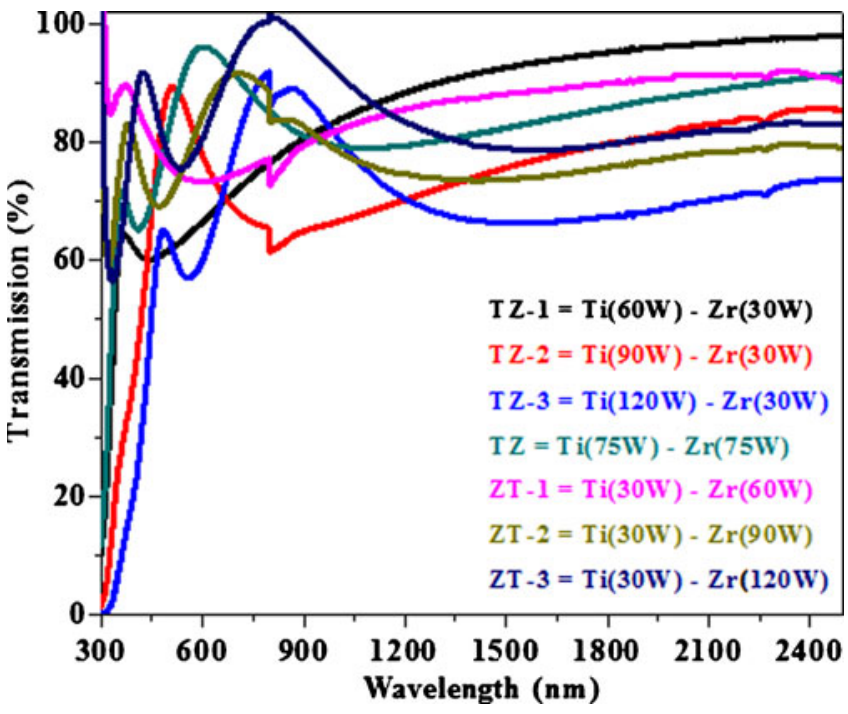

Figure 4. Transmission spectra of titanium and zirconium oxynitride films at varying powers of $\mathrm{Ti}$ and $\mathrm{Zr}$ targets.

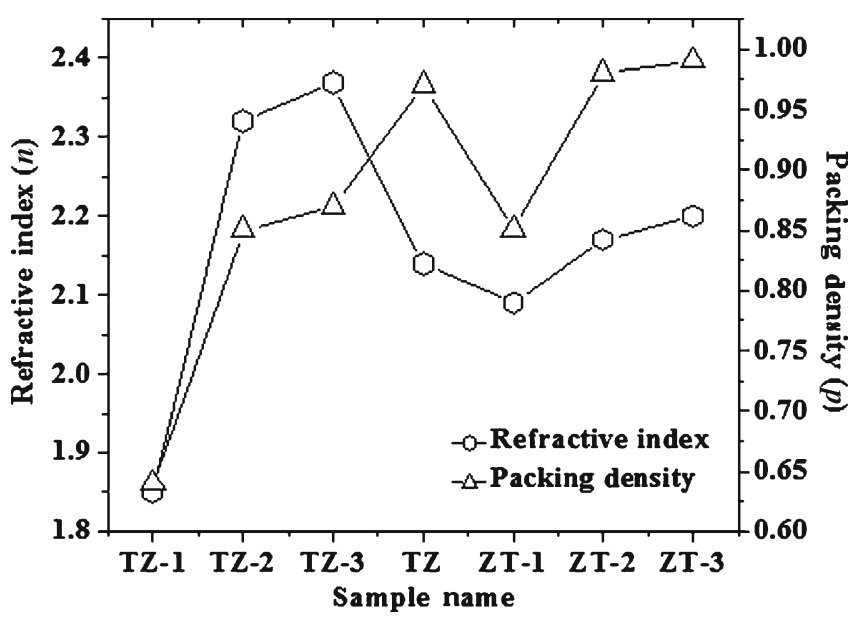

Figure 5. Refractive index vs packing density of titanium and zirconium oxynitride films at varying powers of $\mathrm{Ti}$ and $\mathrm{Zr}$ targets.

of refractive index with film packing density is shown in figure 5. The refractive index of titanium dioxide is 2.79 and zirconium oxide is 2.18 at $800 \mathrm{~nm}$. So the refractive index of deposited titanium oxynitride films is slightly higher than zirconium oxynitride films. Initially at low target powers the film packing density is less giving lower values of refractive index. With the gradual rise of power availability of metal ions with sufficient energy leads to formation of crystalline films thereby increasing the films packing density and giving thicker films.

Tauc (1974) relation was used for finding optical bandgap of the films from the absorption curves of the samples. The process is described in detail elsewhere (Chawla et al 2008). From figure 6, the bandgap of samples deposited with varying titanium power varies from $2.05-2.45 \mathrm{eV}$ as given in table 1 which is within the range of bandgap values of TiN $2.0 \mathrm{eV}$ (Xiao et al 2007) and $\mathrm{TiO}_{2} 3.2 \mathrm{eV}$ (Miao et al 


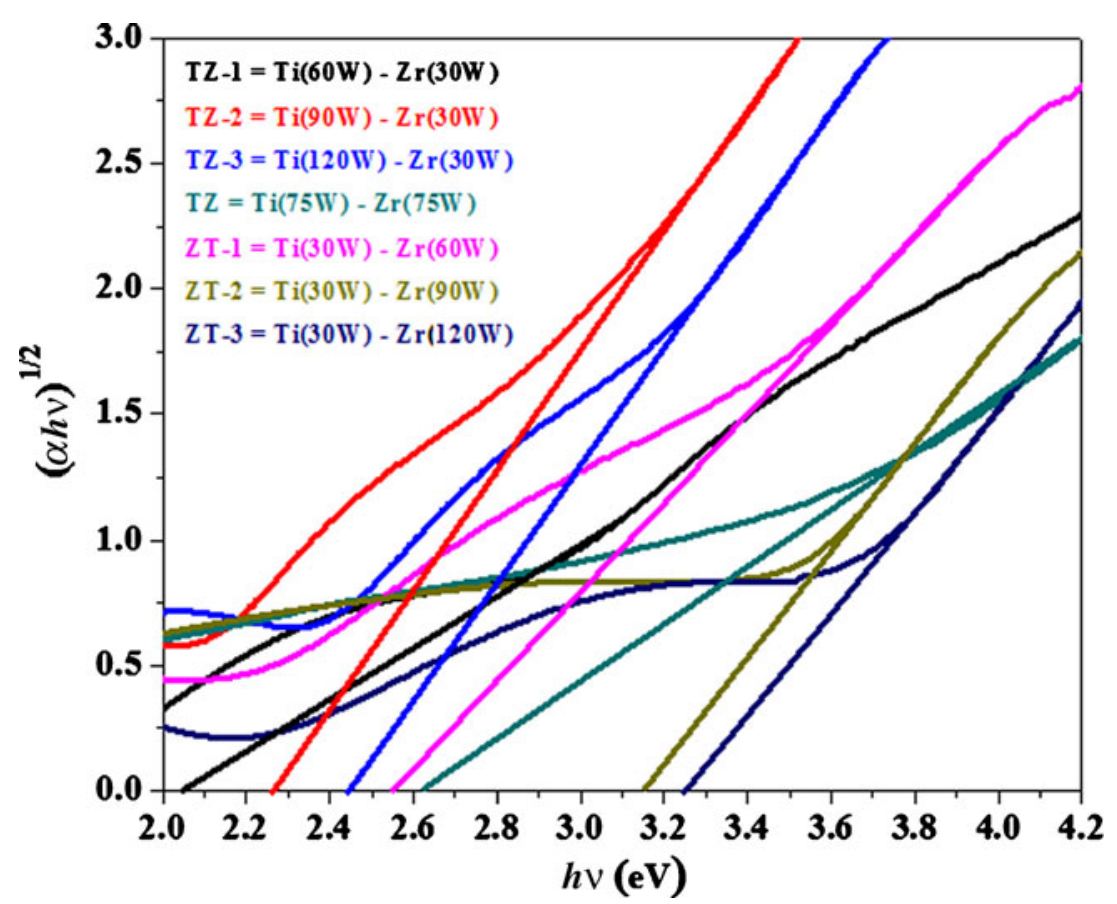

Figure 6. Bandgap of titanium and zirconium oxynitride films at varying powers of $\mathrm{Ti}$ and $\mathrm{Zr}$ targets.

2003; Wu et al 2005) phases observed in literature. The bandgap values of samples deposited with varying zirconium power are found between $2.55-3.25 \mathrm{eV}$ as given in table 1 , whereas the bandgap value of monoclinic zirconium oxide phase reported in literature is $5.42 \mathrm{eV}$ (Karlik et al 1998). The bandgap values of zirconium oxynitride films as reported by Mohamed et al (2007) is around $3.28 \mathrm{eV}$ which they attributed to formation of well-localized $\mathrm{N} 2 p$ states above the $\mathrm{O} 2 p$ valence band states. Inter-relation of such energy levels in the bandgap reduces bandgap and increases the visible light absorption through a charge transfer between a dopant and a conduction or valence band (Valentin et al 2004; Mohamed et al 2007). The formation of zirconium oxynitride phases is observed with incorporation of nitrogen at higher power of $\mathrm{Zr}$ target hence giving lower bandgap values as compared to zirconium oxide but is in agreement with the bandgap values of zirconium oxynitride films as reported in literature. Moreover the probable reason for low bandgap value of sample TZ could be the formation of $m-\mathrm{ZrO}_{2}$ phase in XRD graphs. When the power of both targets are kept equal, may be that there is higher proportion of Ti atoms present as evident from EDS data that may have occupied the interstitial sites in deposited films. But the incorporation of $\mathrm{Ti}$ atoms decreases with the gradual increase of $\mathrm{Zr}$ target power hence, rise in the bandgap values are observed. So the bandgap values observed by us are consistent with those reported in the literature.

\section{Conclusions}

The deposited titanium and zirconium oxynitride films are sensitive to the power variation of both targets. The structural transformation from amorphous to oxide and oxynitride films is observed with gradual increase of target powers. It eventually leads to increase in the deposition rate, thickness and surface roughness of the deposited films. The lowest contact angle value of $67.4^{\circ}$ depicting hydrophilic nature and greater contact angle of $97.5^{\circ}$ for hydrophobic films was observed. Samples TZ-3, ZT-2 and ZT-3 show hydrophobic behaviour due to well-crystalline films as compared to other samples. The rest of the samples show greater surface energy values due to their hydrophilic characteristics. The bandgap values were tailored by varying the chemical composition and structural composition of deposited oxynitride films.

\section{Acknowledgements}

This work has been supported by CSIR grant number 03(1148)/09/EMR-II and DRDO grant number ERIP/ER/0800354/M/011125.

\section{References}

Alves E, Ramos A R, Barradas N P, Vaz F, Cerqueira P, Rebouta L and Kreissig U 2004 Surf. Coat. Technol. 180-181 372

Ariza E et al 2004 Thin Solid Films 469-470 274

Bard A J and Fox M A 1995 Acc. Chem. Res. 28141

Braic M et al 2007 Appl. Surf. Sci. 2538210

Brandt B L, Liu D W and Rubin L G 1999 Rev. Sci. Instrum. 70104

Carvalho P et al 2005 J. Appl. Phys. 98023715

Carvalho P et al 2008 J. Appl. Phys. 103104907

Chappe J M, Gavoille J, Martin N, Lintymer J and Takadoum J 2006 J. Mater. Sci. 415639 
Chawla A K, Singhal S, Gupta H O and Chandra R 2008 Thin Solid Films 5171042

Chen J S, Lau S P, Sun Z, Chen G Y, Li Y J, Tay B K and Chai J W 2001 Thin Solid Films 398110

Chiu S M, Hwang S J, Chu C W and Gan D 2006 Thin Solid Films $\mathbf{5 1 5} 285$

Cullity B D 1978 Elements of X-ray diffraction (London: AddisonWesley) 2nd ed., p. 102

Harris M, Macleod H A and Ogura S 1979 Thin Solid Films 57 173

Hones P, Diserens M and Levy F 1999 Surf. Coat. Technol. 120-121 277

Hsu C H, Huang D H, Ho W Y, Huang L T and Chang C L 2006 Mat. Sci. Eng. A $\mathbf{4 2 9} 212$

Karlik B, Chang E K and Louie S G 1998 Phys. Rev. B57 7027

Kazemeini M H, Berezin A A and Fukuhara N 2000 Thin Solid Films 37270

Khudhayer W J, Sharma R and Karabacak T 2009 Nanotechnology 20275302

Kostov A and Friedrich B 2005 J. Mining Metallurgy B41 113

Kuo D H and Chien C H 2003 Thin Solid Films 42940

Laurikaitis M, Dudonis J and Milcius D 2008 Thin Solid Films 516 1549

Liang W W and Schuster W 1982 Trans. Japan Inst. Met. 23368

Maeda K, Teramura K, Masuda H, Takata T, Saito N, Inoue Y and Domen K 2006 J. Phys. Chem. B 11013107

Manifacier J C, Gasiot J and Fillard J P 1976 J. Phys. E: Sci. Instrum. 91002

Martin N, Banakh O, Santo A M E, Springer S, Sanjines R, Takadoum J and Levy F 2001 Appl. Surf. Sci. 185123

Miao L, Jin P, Kaneko K, Terai A, Gabain N N and Tanemur S 2003 Appl. Surf. Sci. 212-213 255

Mohamed S H, El-Rahman A M A and Ahmed M R 2007 J. Phys. D: Appl. Phys. $\mathbf{4 0} 7057$
Moura C, Carvalho P, Vaz F, Cunha L and Alves E 2006 Thin Solid Films $\mathbf{5 1 5} 1132$

Nieh R E et al 2003 IEEE Trans. Electron Dev. 50333

Ohring M 1991 The material science of thin films (San Diego: Academic)

Owens D K and Wendl R C 1969 J. Appl. Polym. Sci. 131741

Pacheco A P, Prieto C, Guzman R C and Lopez J G 2009 Thin Solid Films $\mathbf{5 1 7} 5415$

Rizzo A, Signore M A, Mirenghi L and Di Luccio T 2009 Thin Solid Films 5175956

Scopel W L, Fantini M C A, Alayo M I and Pereyra I 2002 Thin Solid Films 41359

Signore M A, Rizzo A, Tapfer L, Piscopiello E, Capodieci L and Cappello A 2010 Thin Solid Films 5181943

Tauc J (ed.) 1974 Amorphous and liquid semiconductor (New York: Plenium Press) p. 159

Trapalis C, Giannakopoulou T, Todorova N, Anastasescu C, Anastasescu M and Gartner M 2007 Semiconductor conference. International, Oct. 15 2007-Sept. 17 2007, Sinaia, Romania, 2 p. 303

Valentin C D, Pacchioni G and Selloni A 2004 Phys. Rev. B70 085116.1

Vaz F et al 2004 Thin Solid Films 447-448 449

Venkataraj S, Kappertz O, Jayavel R and Wuttig M 2002 J. Appl. Phys. 922461

Wu P G, Ma C H and Shang J K 2005 Appl. Phys. A81 1411

Wu K R, Wang J J, Liu W C, Chen Z S and Wu J K 2006 Appl. Surf. Sci. 2525829

Xiao W, Yuan J, Zhang Y and Shangguan W 2007 Mat. Chem. Phys. 1056

Xiao Q L, Xu C, Shao S Y, Shao J D and Fan Z X 2009 Vacuum 83 366

Young T 1805 Philos. Trans. R. Soc. London 9255 